\title{
Biorefineries for Sustainable Food-Fuel-Fibre Production: Towards a Circular Economy
}

\author{
Shabbir H. Gheewala ${ }^{1,2 *}$ \\ ${ }^{1}$ The Joint Graduate School of Energy and Environment, King Mongkut's University of Technology Thonburi, 126 Prachauthit, \\ Bangmod, Tungkru, Bangkok 10140, Thailand \\ ${ }^{2}$ Center of Excellence on Energy Technology and Environment, PERDO, Bangkok, Thailand
}

\begin{abstract}
Agriculture and related industries form the backbone of many Asian economies. Not only do they provide food, but they are increasingly proving to be a reliable local source of energy and materials. Biofuels from palm oil and sugarcane are prominent examples where the palm and sugar mills serve as biorefineries providing food, fuels as well as materials. Nevertheless, there are also associated environmental impacts which need to be considered along with economic considerations. A life cycle approach is useful for both environmental as well as economic assessment. In particular eco-efficiency, a tool combining both environmental and economic aspects is very useful to analyze biorefinery configurations and look at the tradeoffs between the environmental and economic aspects. The increase of value-added products from the biorefineries may lead to increased economic benefits but also increased environmental emissions. Indicators such as eco-efficiency show the relative advantages of the enhanced biorefinery system as compared to conventional food or biofuel production systems. Thus, they provide important information to decisionmakers both for industry and policy.
\end{abstract}

Keywords: Biorefinery; Eco-efficiency; Life cycle approach; Oil palm; Sugarcane.

\section{Introduction}

Agriculture is a key economic sector for many countries in Asia. Not only does it provide food for domestic consumption, but agro-industries also support the economy through export of food products. Rice, palm oil, sugar, and cassava are some prominent examples. More recently, however, in addition to food products, the agroindustries are increasingly adapting to the production of liquid transportation fuels or so-called biofuels as well as biochemicals. Many countries in Southeast Asia, particularly, Indonesia, Malaysia, Philippines, Thailand, and Vietnam have been leading in the production of biofuels - biodiesel from palm oil and coconut oil to replace diesel and ethanol from sugarcane, molasses and corn to replace gasoline. These countries have promoted the use of biofuels through blending mandates and economic instruments supporting the introduction of biofuels into the market. Biofuels have been promoted for a number of reasons including inter alia the use of local materials to reduce imports, the use of renewable materials instead of fossil resources, reduction of greenhouse gas emissions by replacing fossil fuels with bio-based fuels as well as stabilizing farmer incomes. All the intended goals are commendable and seem achievable, but are not automatic. Hence, it is necessary to evaluate them using rigorous scientific techniques and identify the conditions and constraints under which they can be successfully achieved. In such evaluations, it is important to look at the entire supply chain in order to avoid transferring problems from one part of the life cycle to another. This is consistent with the idea of a circular economy that is being promoted worldwide. This paper looks at some of the environmental and economic aspects of palm oil and sugarcane biorefineries in Thailand [1-3]. Eco-efficiency is used as a composite indicator including both environmental and economic aspects.

\section{Methods}

The eco-efficiency indicator was first introduced by the World Business Council on Sustainable Development to promote sustainable development in industry. It is by now widely recognized and used internationally and has also been incorporated as an international standard (ISO14045:2012). It is generically defined as the ratio of product or service value to environmental impact. The definitions of both these terms constituting the ratio are, however, flexible depending on the context and goal. In this study, eco-efficiency is defined as shown in Eq.1:

$$
\text { Eco-eff }_{\text {bioref }}=\text { GVA (US\$) / LC-GHG }\left(\mathrm{kgCO}_{2} \mathrm{eq}\right)
$$

where Eco-eff $f_{\text {bioref }}$ is the eco-efficiency of the biorefinery; GVA is the gross value added and LC-GHG is the total (life cycle) greenhouse gas emissions.

* Corresponding author: shabbir_g@jgsee.kmutt.ac.th 
Furthermore, the GVA of the biorefinery is defined as the net output value calculated as the difference between the selling price of the products and the total production cost. The LC-GHG considers the global warming impact of the entire biorefinery chain starting from the crop cultivation until the production of the final products, including all the intermediate transportation and production processes (Fig. 1).

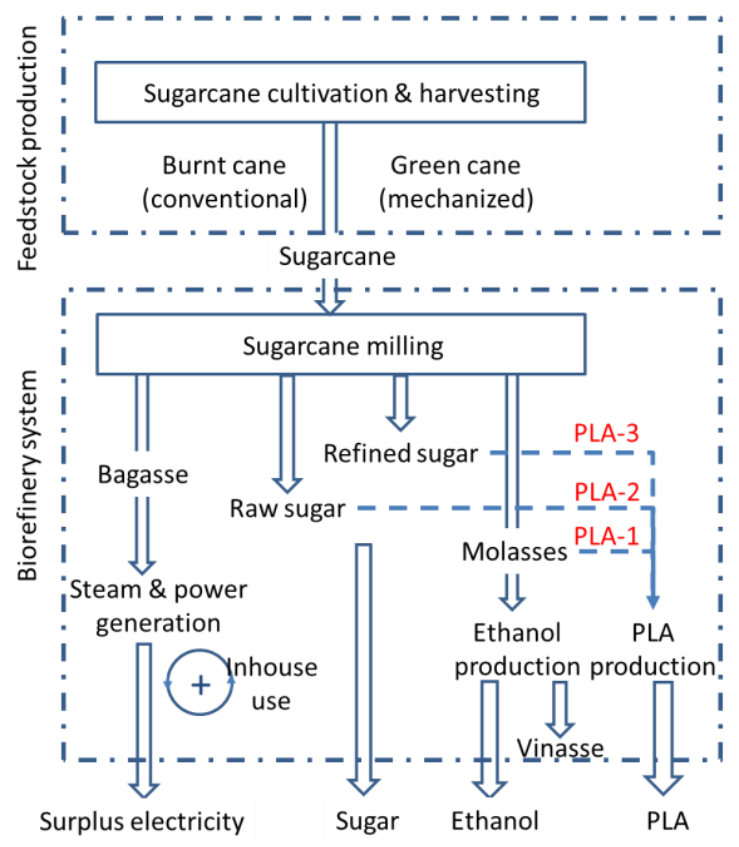

Fig. 1. Sugarcane biorefinery

The results of two previous studies are combined for the case of the sugarcane biorefinery, one is a conventional biorefinery considering a comparative assessment of mechanized and conventional sugarcane farming. The scenarios for this study are outlined in Table $1[1]$.

Table 1. Scenarios for conventional sugarcane biorefinery

\begin{tabular}{|l|l|}
\hline System & Description \\
\hline Base case & $\begin{array}{l}\text { Conventional farming + sugarcane milling + } \\
\text { ethanol production + electricity production }\end{array}$ \\
\hline Scen. 1 (S1) & $\begin{array}{l}\text { Mechanical farming + sugarcane milling + } \\
\text { ethanol production + electricity production }\end{array}$ \\
\hline Scen. 2 (S2) & $\begin{array}{l}\text { S1 + 50\% cane trash recovered for } \\
\text { electricity }\end{array}$ \\
\hline Scen. 1 (S3) & S2 + vinasse utilization as fertilizer \\
\hline
\end{tabular}

The other study looks at an advanced sugarcane biorefinery with three new sugar-electricity-polylactic acid (PLA) systems and compares them to the existing sugar-electricity-ethanol system (Table 2) [2]. For the second study, the denominator term in Eq. 1 uses a single score combining multiple environmental impacts using the ReCiPe 2016 life cycle impact assessment method instead of only the LC-GHG emissions (Eq. 2).
Eco-eff bioref $=$ GVA (US\$) / Env-Imp (Pt)

where Eco-eff $f_{\text {bioref }}$ is the eco-efficiency of the biorefinery; GVA is the gross value added and Env-Imp is the total environmental impacts expressed as a single score using the ReCiPe 2016 endpoint method.

The average production data for sugarcane cultivation were collected from about 800 farmers and sugarcane milling from 20 sugar factories in Thailand [1]. The data for PLA production was from the literature $[4,5]$

Table 2. Scenarios for advanced sugarcane biorefinery

\begin{tabular}{|l|l|}
\hline System & Description \\
\hline Base case & $\begin{array}{l}\text { Sugarcane farming + sugarcane milling }+ \\
\text { ethanol production + electricity production }\end{array}$ \\
\hline PLA-1 & $\begin{array}{l}\text { Base case + molasses used for PLA } \\
\text { production }\end{array}$ \\
\hline PLA-2 & PLA-1 + raw sugar used for PLA production \\
\hline PLA-3 & All sugar and molasses for PLA production \\
\hline
\end{tabular}

The second biorefinery chain studied is that of oil palm (Fig. 2).

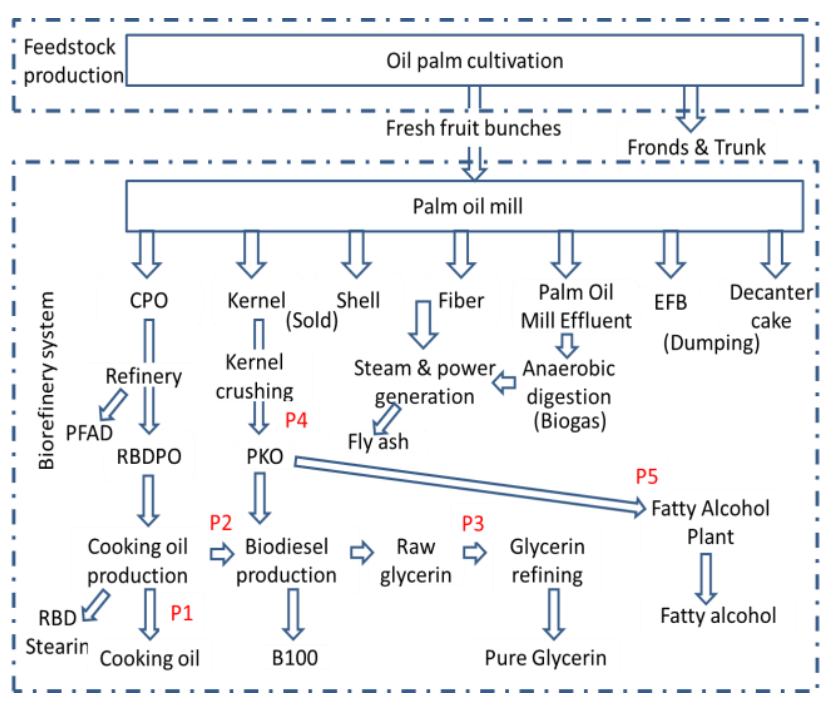

Fig. 2. Palm oil biorefinery (PFAD: Palm Fatty Acid Distillate; RBD: Refined, bleached, deodorized)

The system boundary includes the oil palm cultivation, transportation of fresh fruit bunches (FFB) to the palm oil mill and subsequent milling to produce crude palm oil (CPO) and palm kernels along with various by-products such as fibre, shell, empty fruit bunches (EFB), decanter cake and palm oil mill effluent (POME). The CPO is further refined to produce refined, bleached, deodorized palm oil (RBDPO) which can be used as cooking oil or further processed to produce biodiesel (B100). The palm kernels can be either be sold off or milled to produce palm kernel oil (PKO) which can further be processed into B100 or fatty alcohol. The raw glycerine, produced as a by-product during the production of B100, can be purified to produce pure glycerine which has many high-end applications. The shell and fibre are used internally for 
steam and power production. The excess shells are sold. The POME is treated anaerobically to produce biogas which is also used further for steam and power production. The EFB and decanter cake are generally dumped in the oil palm plantations. Considering the multiple possible uses of the various products and byproducts, a set of scenarios outlined in Table 3 are considered for evaluation [3]. The eco-efficiency of the biorefinery options is calculated following Eq. 1.

Table 3. Scenarios for palm oil biorefinery

\begin{tabular}{|l|l|}
\hline System & Description \\
\hline P1 & $\begin{array}{l}\text { CPO for cooking oil + kernel being sold (base } \\
\text { case) }\end{array}$ \\
\hline P2 & CPO for biodiesel + kernel being sold \\
\hline P3 & P-2 + raw glycerin refined to pure glycerin \\
\hline P4 & CPO and kernel for biodiesel \\
\hline P5 & P-3 + kernel for fatty acid \\
\hline
\end{tabular}

\section{Results and discussion}

The evaluation results of the conventional sugarcane biorefinery are shown in Fig. 3. It is clear that moving from conventional (base case) to mechanized (S1) farming reduces the LC-GHG emissions. Even though mechanization increases the diesel used in machinery leading to higher GHG emissions, this is more than compensated by the avoided open pre-harvest burning of cane trash in the conventional farming system. Although the GVA remains the same as the products do not change, the eco-efficiency of the biorefinery system increases. For S2, utilization of $50 \%$ of the cane trash for power production results in substantial GHG reduction as well as economic benefits leading to a substantially higher ecoefficiency. The utilization of vinasse in S3 does not yield many economic benefits as it is given out free to the farmers by the sugar mills; however, there is a small GHG benefit leading to a slightly higher eco-efficiency. Overall, the improved biorefinery systems result in a 20 $70 \%$ increase in eco-efficiency as compared to the base case.

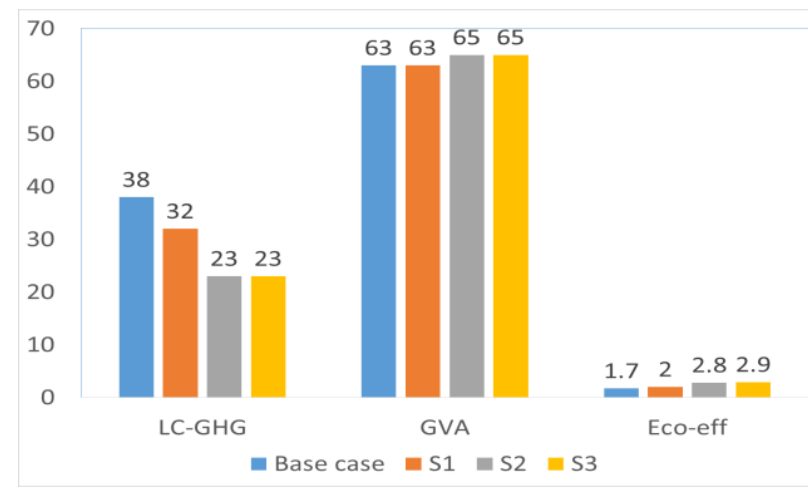

Fig. 3. Eco-efficiency values for conventional sugarcane biorefinery (LC-GHG in $\mathrm{kgCO}_{2} \mathrm{eq} / \mathrm{t}$ cane; GVA in US\$/t cane; Eco-eff bioref in $\left.\mathrm{US} \$ / \mathrm{kgCO}_{2} \mathrm{eq}\right)$
For the advanced sugarcane biorefinery, on the other hand, the results of the environmental impacts keep increasing as more PLA is produced (Fig. 4). PLA production requires a large amount of grid electricity for lactic acid production, lactide synthesis and purification, and PLA production [4]. This, along with chemicals (particularly sulphuric acid) required in the processing, has a significant contribution to the environmental impacts. However, the GVA also increases with increased production of PLA; more production results in more impacts and also more value-added. Here, the role of ecoefficiency as a useful indicator for analysis becomes even clearer. The eco-efficiency results indicate that PLA-2 and PLA-3, with a higher amount of PLA production perform the best; however, even PLA-1 is better than the base case.

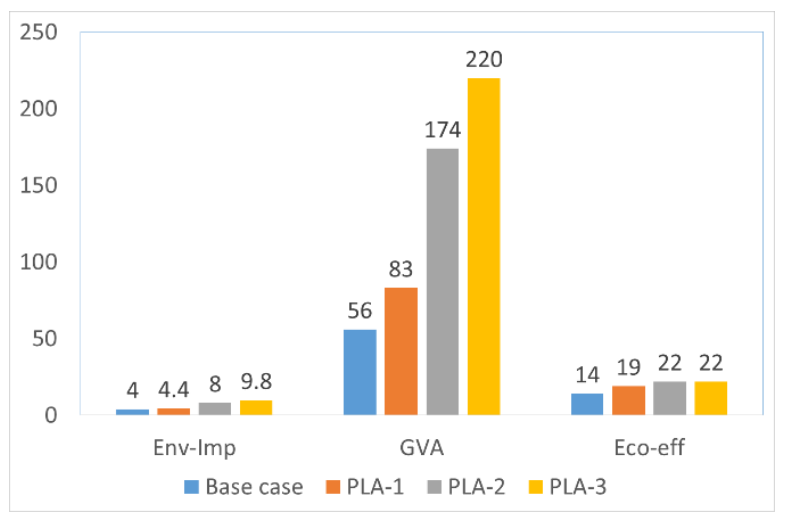

Fig. 4. Eco-efficiency values for advanced sugarcane biorefinery (Env-Imp in Pt/t cane; GVA in US\$/t cane; Eco-

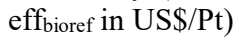

The eco-efficiency results for the various palm oil biorefinery configurations are presented in Fig. 5. The base case (P1) is represented by all the CPO being used for the production of cooking oil, the kernels and excess shells being sold. The production of fuel and chemicals has $13-24 \%$ higher eco-efficiency values than the base case where cooking oil is produced. Once again, even though the LC-GHG values for all the scenarios (P2-P5) are higher than the base case $(\mathrm{P} 1)$ due to additional processes being needed, the higher GVAs more than compensate for that. For the scenario P3, even though the price of pure glycerine is almost twice than of raw glycerine, the low conversion efficiency of the factory (about $57 \%$ ) results in a relatively lower eco-efficiency value. This is something that can and needs to be improved for better performance of this biorefinery option. 




Fig. 5. Eco-efficiency values for palm oil biorefinery (LC-GHG in $\mathrm{kgCO}_{2} \mathrm{eq} / \mathrm{t} \mathrm{FFB}$; GVA in US\$/t FFB; Eco-eff bioref in $\left.\mathrm{US} \$ / \mathrm{kgCO}_{2} \mathrm{eq}\right)$

\section{Conclusion}

The study shows the advantages of using a biorefinery concept for food, fuel and chemical production as a step towards a circular economy where all parts of an agricultural product, including waste, are optimally utilized. The eco-efficiency indicator is proven to be an important tool that helps reveal and analyze trade-offs between the value-added and environmental impacts of the biorefinery configurations. Though from a strong sustainability perspective, the ideal case would be to reduce environmental impacts while increasing economic value (complete decoupling of environment and economy), eco-efficiency can give a general idea on whether there is an overall improvement or not should environmental impacts increase along with the economic value. The conventional sugarcane biorefinery shows the clear advantage of using mechanized harvesting that avoids the open burning of cane trash. Utilization of the cane trash for power production further increases the ecoefficiency of the biorefinery system. Utilization of the cane trash and vinasse results in the highest eco-efficiency among all the options compared. The production of PLA in advanced sugarcane biorefinery configurations further enhances the eco-efficiency. Here, even though the added process of PLA production increases the environmental impacts, the increase in GVA more than compensates for that as revealed by the increase in eco-efficiency values. Analysing the details of the life cycle indicates that the eco-efficiency can be increased even further by improving the sugarcane cultivation and harvesting practices as well as increasing the co-generation technology using higher pressure boilers in the steam and power production. A similar observation can be made also for the palm oil biorefinery where the production of fuel and chemicals results in increased eco-efficiency values even though the LC-GHG is also increased due to the introduction of new processes for fuel and chemicals production. Here too, increasing the oil palm yield through improved agricultural practices (optimized application of fertilizers and water) and increased oil extraction rates can result in a substantial increase in eco-efficiency.

\section{References}

1. T. Silalertruksa, S.H. Gheewala, P. Pongpat, Appl. Energ. 160, 603-609 (2015)

2. T. Silalertruksa, S.H. Gheewala, Int. J. Life Cycle Assess. (in press) (2019)

3. T. Silalertruksa, S.H. Gheewala, P. Nilsalab, N. Lecksiwilai, K. Changwichan, N. Permpool, N. Huailuek, Proceedings of the 11th International Conference on Ecobalance, Tokyo, Japan (2018)

4. W.J. Groot, T. Borén, Int J Life Cycle Assess. 15, 970-984 (2010)

5. K. Changwichan, T. Silalertruksa, S.H. Gheewala, Sustainability 10, 952 (2018) 